Journal of Bangladesh Academy of Sciences, Vol. 33, No. 2, 199-208, 2009

\title{
CHARACTERIZATIONS OF PRINCIPAL n-IDEALS IN TERMS OF RELATIVELY NORMAL NEARLATTICES
}

\author{
M. S. RAIHAN \\ Department of Mathematics, University of Rajshahi, Rajshahi-6205, Bangladesh.
}

(Received revised copy: July 8, 2009)

\section{ABSTRACT}

In this paper, we have characterized the principal n-ideals of relatively normal nearlattices which are generalizations of several results on relatively normal nearlattices. We have also shown that for a central element $n$, the set of principal n-ideals is relatively normal if and only if any two incomparable prime n-ideals of $\mathrm{S}$ are co-maximal.

\section{INTRODUCTION}

n-Normal in lattices and n-Normal in nearlattices have been studied by many authors including [1], [2] and [3]. Also [5] has used the annihilators in case of relative normal lattices. In this paper, we introduce the notion of principal n-ideals of relatively normal nearlattices which are generalizations of several results on relatively normal nearlattices.

A distributive nearlattice $S$ is called a relatively normal nearlattice if each closed interval $[\mathrm{x}, \mathrm{y}]$ with $\mathrm{x}<\mathrm{y}(\mathrm{x}, \mathrm{y} \in \mathrm{S})$ is a normal lattice. In [13, Chapter 2] discusses the concept of normality in a bounded distributive lattice which is self dual. So the concept of relative normality in a nearlattice is also self dual.

An element $\mathrm{n}$ in a nearlattice $\mathrm{S}$ is called sesquimedial if for all $\mathrm{x}, \mathrm{y}, \mathrm{z} \in \mathrm{S}$,

$$
([(\mathrm{x} \wedge \mathrm{n}) \vee(\mathrm{y} \wedge \mathrm{n})] \wedge[(\mathrm{y} \wedge \mathrm{n}) \vee(\mathrm{z} \wedge \mathrm{n})]) \vee(\mathrm{x} \wedge \mathrm{y}) \vee(\mathrm{y} \wedge \mathrm{z}) \text { exists in } \mathrm{S} \text {. }
$$

An element $\mathrm{n}$ of a nearlattice $\mathrm{S}$ is called an upper element if $\mathrm{x} \vee \mathrm{n}$ exists for all $\mathrm{x} \in \mathrm{S}$. Every upper element is of course a sesquimedial element.

An element $\mathrm{n}$ is called a central element of $\mathrm{S}$ if it is neutral, upper complemented in each interval containing it.

An n-ideal generated by a single element a is called a principal n-ideal, denoted by < $a>_{n}$. The set of principal n-ideals is denoted by $P_{n}(S)$.

In this paper, we have characterized those $\mathrm{P}_{\mathrm{n}}(\mathrm{S})$ which are relatively normal in terms of $n$-ideals and relative n-annihilators. These results are certainly generalizations of several results on relatively normal nearlattices given by [9]. At the end, we have shown that, for a central element $n, P_{n}(S)$ is relatively normal if and only if any two incomparable prime n-ideals of $\mathrm{S}$ are co-maximal.

1. Some characterizations of those $P_{n}(S)$ which are Relatively Normal Nearlattices.

A distributive nearlattice $S$ is relatively normal if each interval $[x, y]$ in 


$$
S(x, y \in S) x<y \text {, is normal. }
$$

When $n$ is a sesquimedial element of a distributive nearlattice $S$, then $P_{n}(S)$ is also a distributive nearlattice. Thus, $P_{n}(S)$ is a relatively normal nearlattice if each interval

$$
\left[<\mathrm{a}>_{\mathrm{n}},<\mathrm{b}>_{\mathrm{n}}\right] \text { in } \mathrm{P}_{\mathrm{n}}(\mathrm{S}) \text { is normal. }
$$

The following result [11] will be needed for the further development of this section.

Theorem 1.1 Let S be a distributive nearlattice with an upper element $\mathrm{n}$. Then the following conditions hold.

(i) $<<\mathrm{x}>_{\mathrm{n}} \vee<\mathrm{y}>_{\mathrm{n}},<\mathrm{x}>_{\mathrm{n}}>=<<\mathrm{y}>_{\mathrm{n}},<\mathrm{x}>_{\mathrm{n}}>$.

(ii) $\left\langle<\mathrm{x}>_{\mathrm{n}}, \mathrm{J}\right\rangle=\mathrm{v}_{\mathrm{y} \in \mathrm{J}}<\left\langle\mathrm{x}>_{\mathrm{n}},<\mathrm{y}>_{\mathrm{n}}>\right.$, the supremum of $\mathrm{n}$-ideal $<<\mathrm{x}>_{\mathrm{n}}$, $\left.<\mathrm{y}\rangle_{\mathrm{n}}\right\rangle$ in the lattice of $\mathrm{n}$-ideals of $\mathrm{S}$, for any $\mathrm{x} \in \mathrm{S}$ and any $\mathrm{n}$-ideal $\mathrm{J}$.

Lemma 1.2[5, Lemma 3.6] Let L be a lattice. Then the following hold.

(a) $<\mathrm{x} \vee \mathrm{y}, \mathrm{x}>=<\mathrm{y}, \mathrm{x}>$ for any $\mathrm{x}, \mathrm{y} \in \mathrm{L}$,

(b) $<$ (x], $\mathrm{J}>=\vee_{\mathrm{y} \in \mathrm{J}}<\mathrm{x}, \mathrm{y}>$, the supremum of ideals $<\mathrm{x}, \mathrm{y}>$ in the lattice of ideals of $\mathrm{L}$, for any $\mathrm{x} \in \mathrm{L}$ and any ideal $\mathrm{J}$ in $\mathrm{L}$.

(c) $\{<\mathrm{x}, \mathrm{a}>\mathrm{v}<\mathrm{y}, \mathrm{a}>\} \cap[\mathrm{a}, \mathrm{b}]=\{<\mathrm{x}, \mathrm{a}>\cap[\mathrm{a}, \mathrm{b}]\} \vee\{<\mathrm{y}, \mathrm{a}>\cap[\mathrm{a}, \mathrm{b}]\}$ for any $\mathrm{x}, \mathrm{y} \in[\mathrm{a}, \mathrm{b}], \mathrm{a}<\mathrm{b}$.

Theorem 1.3[5, Theorem 3.7] Let a, b and c be arbitrary elements of a lattice L. Let $\mathrm{A}, \mathrm{B}$ and $\mathrm{C}$ be arbitrary ideals in $\mathrm{L}$. Then the following are equivalent:

(a) $\mathrm{L}$ is relatively normal,

(b) $<$ a, b $>$ v $<$ b, a $>=$ L,

(c) $<$ c, a $\vee$ b $>=<$ c, a $>\vee<$ c, b $>$,

(d) $<$ (c], A $\vee$ B $>=<$ (c], A $>\vee<$ (c], B $>$,

(e) $<$ a $\wedge$ b, c $>=<$ a, c $>\vee<$ b, c $>$,

(f) $<$ (a] $\cap$ (b], C $>=<$ (a], C $>\vee<$ (b], C $>$.

Following lemma is dual of Lemma 1.2 and is very easy to prove. So we prefer to omit the proof.

Lemma 1.4 Let L be distributive lattice. Then the following conditions hold.

(i) $<x \wedge y, x>_{d}=<y, x>_{d}$.

(ii) $<[\mathrm{x}), \mathrm{F}>_{\mathrm{d}}=\vee_{\mathrm{y} \in \mathrm{F}}<\mathrm{x}, \mathrm{y}>_{\mathrm{d}}$, where $\mathrm{F}$ is a filter of $\mathrm{L}$.

(iii) $\left\{<\mathrm{x}, \mathrm{a}>_{\mathrm{d}} \vee<\mathrm{y}, \mathrm{a}>_{\mathrm{d}}\right\} \cap[\mathrm{a}, \mathrm{b}]=\left\{<\mathrm{x}, \mathrm{a}>_{\mathrm{d}} \cap[\mathrm{a}, \mathrm{b}]\right\} \vee\left\{\left\langle\mathrm{y}, \mathrm{a}>_{\mathrm{d}} \cap[\mathrm{a}, \mathrm{b}]\right\}\right.$, where $[\mathrm{a}, \mathrm{b}]$ represents any interval in $\mathrm{L}$. 
Lemma 1.5 and Lemma 1.6, which are also due to [11], are essential for the proof of our main result of this section.

Lemma 1.5 Let S be a distributive nearlattice with an upper element $\mathrm{n}$. Suppose a, b, $\mathrm{c} \in \mathrm{S}$.

(i) If a,b, $\mathrm{c} \geq \mathrm{n}$, then $\left.\langle<\mathrm{m}(\mathrm{a}, \mathrm{n}, \mathrm{b})\rangle_{\mathrm{n}},\langle\mathrm{c}\rangle_{\mathrm{n}}\right\rangle=\left\langle\langle\mathrm{a}\rangle_{\mathrm{n}},\langle\mathrm{C}\rangle_{\mathrm{n}}\right\rangle \mathrm{V}$ $\left.\langle<\mathrm{b}\rangle_{\mathrm{n}},\langle\mathrm{c}\rangle_{\mathrm{n}}\right\rangle$ is equivalent to $\langle\mathrm{a} \wedge \mathrm{b}, \mathrm{c}\rangle=\langle\mathrm{a}, \mathrm{c}\rangle \mathrm{v}\langle\mathrm{b}, \mathrm{c}\rangle$.

(ii) If a, b, c $\leq \mathrm{n}$, then $\left.<<\mathrm{m}(\mathrm{a}, \mathrm{n}, \mathrm{b})>_{\mathrm{n}},\langle\mathrm{c}\rangle_{\mathrm{n}}\right\rangle=\left\langle\langle\mathrm{a}\rangle_{\mathrm{n}},\langle\mathrm{c}\rangle_{\mathrm{n}}\right\rangle_{\mathrm{V}}$ $\left.<\langle\mathrm{b}\rangle_{\mathrm{n}},\langle\mathrm{c}\rangle_{\mathrm{n}}\right\rangle$ is equivalent to $\langle\mathrm{a} \vee \mathrm{b}, \mathrm{c}\rangle_{\mathrm{d}}=\langle\mathrm{a}, \mathrm{c}\rangle_{\mathrm{d}} \vee\langle\mathrm{b}, \mathrm{c}\rangle_{\mathrm{d}}$.

Lemma 1.6 Let S be a distributive nearlattice with an upper element $\mathrm{n}$. Suppose a, b, $\mathrm{c} \in \mathrm{S}$.

(i) If a, b, c $\geq \mathrm{n}$ and a $\vee$ b exists, then $\left\langle\langle\mathrm{c}\rangle_{\mathrm{n}},\langle\mathrm{a}\rangle_{\mathrm{n}} \vee\langle\mathrm{b}\rangle_{\mathrm{n}}\right\rangle=\left\langle\langle\mathrm{C}\rangle_{\mathrm{n}}\right.$, $\left.\langle\mathrm{a}\rangle_{\mathrm{n}}\right\rangle \mathrm{v}\left\langle\langle\mathrm{c}\rangle_{\mathrm{n}},\langle\mathrm{b}\rangle_{\mathrm{n}}\right\rangle$ is equivalent to $\langle\mathrm{c}, \mathrm{a} \vee \mathrm{b}\rangle=\langle\mathrm{c}$, a $\left.\rangle \vee<\mathrm{c}, \mathrm{b}\right\rangle$.

(iii) If a, b, $\mathrm{c} \leq \mathrm{n}$, then $\left.\left.\langle<\mathrm{c}\rangle_{\mathrm{n}},\langle\mathrm{a}\rangle_{\mathrm{n}} \vee<\mathrm{b}\right\rangle_{\mathrm{n}}\right\rangle=\left\langle\langle\mathrm{c}\rangle_{\mathrm{n}},\langle\mathrm{a}\rangle_{\mathrm{n}}\right\rangle \mathrm{v}$ $\left\langle\langle\mathrm{c}\rangle_{\mathrm{n}},\langle\mathrm{b}\rangle_{\mathrm{n}}\right\rangle$ is equivalent to $\langle\mathrm{c}, \mathrm{a} \wedge \mathrm{b}\rangle_{\mathrm{d}}=\langle\mathrm{c}, \mathrm{a}\rangle_{\mathrm{d}} \vee\langle\mathrm{c}, \mathrm{b}\rangle_{\mathrm{d}}$.

The following result is due to [11], which is a generalization of above Lemma-1.2, which plays an important role in proving our main result in this paper.

Theorem 1.7 Let S be a distributive nearlattice. Then the following conditions hold.

(i) $\left.\left.<\langle\mathrm{x}\rangle_{\mathrm{n}} \vee<\mathrm{y}\right\rangle_{\mathrm{n}},\langle\mathrm{x}\rangle_{\mathrm{n}}\right\rangle=\left\langle\langle\mathrm{y}\rangle_{\mathrm{n}},\langle\mathrm{x}\rangle_{\mathrm{n}}\right\rangle$.

(ii) $\left\langle\langle\mathrm{x}\rangle_{\mathrm{n}}, \mathrm{J}\right\rangle=v_{\mathrm{y} \in \mathrm{J}}\left\langle\langle\mathrm{x}\rangle_{\mathrm{n}},\langle\mathrm{y}\rangle_{\mathrm{n}}\right\rangle$, the supremum of $\mathrm{n}$-ideals

$\left.<<\mathrm{x}\rangle_{\mathrm{n}},\langle\mathrm{y}\rangle_{\mathrm{n}}\right\rangle$ in the lattice of $\mathrm{n}$-ideals of $\mathrm{L}$, for any $\mathrm{x} \in \mathrm{L}$ and any $\mathrm{n}$-ideal $\mathrm{J}$.

Recall that a distributive lattice $\mathrm{L}$ with 1 is a dual normal lattice if $\mathrm{L}^{\mathrm{d}}$ is a normal lattice. In other words, a distributive lattice $L$ with 1 is called dual normal if every prime filter of $\mathrm{L}$ is contained in a unique ultra filter (maximal and proper) of $\mathrm{L}$. As we mentioned earlier that this condition in a lattice is self dual. Thus for a bounded distributive lattice, the concept of normality and dual normality coincides.

Following the technique of the proof of [5, Theorem 2.4], we can prove the following result, which gives some characterization of dual normal lattices. These results are in fact, the dual result of [14, Theorem 1.3].

Theorem 1.8 Let L be a distributive lattice with 1. Then the following conditions are equivalent.

(i) L is dual normal.

(ii) Each prime filter of $\mathrm{L}$ is contained in a unique ultra-filter (maximal and proper). 
(iii) For each $\mathrm{x}, \mathrm{y} \in \mathrm{L},[\mathrm{x} \vee \mathrm{y})^{* \mathrm{~d}}=[\mathrm{x})^{* \mathrm{~d}} \vee[\mathrm{y})^{* \mathrm{~d}}$.

(iv) If $\mathrm{x} \vee \mathrm{y}=1, \mathrm{x}, \mathrm{y} \in \mathrm{L}$, then $[\mathrm{x})^{* \mathrm{~d}} \vee[\mathrm{y})^{* \mathrm{~d}}=\mathrm{L}$.

Corollary 1.9 Let L be a bounded distributive lattice. Then the following conditions are equivalent.

(i) L is normal.

(ii) For each $\mathrm{x}, \mathrm{y} \in \mathrm{L},(\mathrm{x} \wedge \mathrm{y}]^{*}=(\mathrm{x}]^{*} \vee(\mathrm{y}]^{*}$.

(iii) If $\mathrm{x} \wedge \mathrm{y}=0$, then $(\mathrm{x}]^{*} \vee(\mathrm{y}]^{*}=\mathrm{L}$.

(iv) For each $\mathrm{x}, \mathrm{y} \in \mathrm{L},[\mathrm{x} \vee \mathrm{y})^{* \mathrm{~d}}=[\mathrm{x})^{* \mathrm{~d}} \vee[\mathrm{y})^{* \mathrm{~d}}$.

(v) If $\mathrm{x} \vee \mathrm{y}=1$, then $[\mathrm{x})^{* \mathrm{~d}} \vee[\mathrm{y})^{* \mathrm{~d}}=\mathrm{L}$.

Ali in [4, Theorem 3.2.7.] has given a nice characterization of relatively normal lattices in terms of dual relative annihilators, which is in fact, the dual of Theorem 1.3. As we have mentioned earlier that in nearlattices the idea of dual relative annihilators is not always possible. But when $\mathrm{n}$ is an upper element in $\mathrm{S}$ then $\mathrm{x} \vee \mathrm{n}$ exists for all $\mathrm{x} \in \mathrm{S}$. Thus for any $a \in(n], x \vee$ a exists for $\mathrm{x} \in \mathrm{S}$. Hence we can define

$$
<\mathrm{a}, \mathrm{b}>_{\mathrm{d}} \text { for all } \mathrm{a} \in(\mathrm{n}] \text { and } \mathrm{b} \in \mathrm{S} \text {. }
$$

When $\mathrm{n}$ is a central element in $\mathrm{S}$, then by [13, Theorem 1.5.2], $\mathrm{P}_{\mathrm{n}}(\mathrm{S}) \cong(\mathrm{n}]^{\mathrm{d}} \times[\mathrm{n})$.

Thus we have the following result.

Proposition 1.10 For a distributive nearlattice $\mathrm{S}$ with a central $\mathrm{n}, \mathrm{P}_{\mathrm{n}}(\mathrm{S})$ is relatively normal if and only if (n] and [n) are relatively normal.

Now we prove the following important result for distributive nearlattice in terms of relatively normal nearlattice.

Theorem 1.11 Let $\mathrm{n}$ be a central element of a distributive nearlattice $\mathrm{S}$ such that (n] is relatively normal. Let $\mathrm{a}, \mathrm{b}, \mathrm{c} \in(\mathrm{n}]$ be arbitrary elements and $\mathrm{A}, \mathrm{B}$ be arbitrary filters on (n]. Then the following conditions are equivalent.

(i) (n] is relatively normal.

(ii) $<$ a, b $>_{\mathrm{d}} \vee<\mathrm{b}, \mathrm{a}>_{\mathrm{d}}=$ (n].

(iii) $<$ c, a $\wedge$ b $>_{\mathrm{d}}=<\mathrm{c}, \mathrm{a}>_{\mathrm{d}} \vee<\mathrm{c}, \mathrm{b}>_{\mathrm{d}}$.

(iv) $<$ [c), $\mathrm{A} \vee \mathrm{B}>_{\mathrm{d}}=<[\mathrm{c}), \mathrm{A}>_{\mathrm{d}} \vee<[\mathrm{c}), \mathrm{B}>_{\mathrm{d}}$.

(v) $\langle\mathrm{a} \vee \mathrm{b}, \mathrm{c}\rangle_{\mathrm{d}}=\langle\mathrm{a}, \mathrm{c}\rangle_{\mathrm{d}} \vee\langle\mathrm{b}, \mathrm{c}\rangle_{\mathrm{d}}$.

Proof. (i) $\Rightarrow$ (ii). Suppose (i) holds. Let $\mathrm{z} \in(\mathrm{n}]$ be arbitrary. Consider the interval $\mathrm{I}=[\mathrm{z}, \mathrm{a} \vee \mathrm{b} \vee \mathrm{z}]$. Then $\mathrm{a} \vee \mathrm{b} \vee \mathrm{z}$ is the largest element of I. Since by (i), I is normal, then by Theorem [5, Theorem 2.4], there exists $\mathrm{r}, \mathrm{s} \in \mathrm{I}$ such that $\mathrm{a} \vee \mathrm{s}=\mathrm{a} \vee \mathrm{b} \vee \mathrm{z}=\mathrm{b} \vee \mathrm{z}$ 
$\vee \mathrm{r}$ and $\mathrm{z}=\mathrm{s} \wedge \mathrm{r}$. Now, $\mathrm{a} \vee \mathrm{s} \geq \mathrm{b}$ implies $\mathrm{s} \in<\mathrm{a}, \mathrm{b}>_{\mathrm{d}}$ and

$\mathrm{b} \vee \mathrm{r}=\mathrm{b} \vee \mathrm{z} \vee \mathrm{r}=\mathrm{a} \vee \mathrm{b} \vee \mathrm{z} \geq \mathrm{a}$ implies $\mathrm{r} \in<\mathrm{b}, \mathrm{a}>_{\mathrm{d}}$. Hence (ii) holds.

(ii) $\Rightarrow$ (iii). Suppose (ii) holds. In (iii), R.H.S. $\subseteq$ L.H.S. is obvious.

Let $\mathrm{z} \in<\mathrm{c}, \mathrm{a} \wedge \mathrm{b}>_{\mathrm{d}}$, then $\mathrm{z} \vee \mathrm{c} \geq \mathrm{a} \wedge \mathrm{b}$. Since (ii) holds, so $\mathrm{z}=\mathrm{x} \wedge \mathrm{y}$ where $\mathrm{x} \in<\mathrm{a}, \mathrm{b}>_{\mathrm{d}}$ and $\mathrm{y} \in<\mathrm{b}, \mathrm{a}>_{\mathrm{d}}$. Then $\mathrm{x} \vee \mathrm{a} \geq \mathrm{b}$ and $\mathrm{y} \vee \mathrm{b} \geq \mathrm{a}$.

Thus, $\mathrm{x} \vee \mathrm{c}=\mathrm{x} \vee \mathrm{z} \vee \mathrm{c}$

$$
\begin{aligned}
& \geq \mathrm{x} \vee(\mathrm{a} \wedge \mathrm{b}) \\
& =(\mathrm{x} \vee \mathrm{a}) \wedge(\mathrm{x} \vee \mathrm{b}) \geq \mathrm{b} \text {, which implies } \mathrm{x} \in<\mathrm{c}, \mathrm{b}>_{\mathrm{d}}
\end{aligned}
$$

Similarly, $\mathrm{y} \in<\mathrm{c}, \mathrm{a}\rangle_{\mathrm{d}}$. Hence $\mathrm{z}=\mathrm{x} \wedge \mathrm{y} \in\langle\mathrm{c}, \mathrm{a}\rangle_{\mathrm{d}} \vee\langle\mathrm{c}, \mathrm{b}\rangle_{\mathrm{d}}$ and so $<$ c, a $\wedge$ b $>_{\mathrm{d}} \subseteq<\mathrm{c}, \mathrm{a}>_{\mathrm{d}} \vee<\mathrm{c}, \mathrm{b}>_{\mathrm{d}}$. Thus (iii) holds.

(iii) $\Rightarrow$ (iv) follows from Lemma 1.4 (ii).

(iv) $\Rightarrow$ (iii) is trivial.

(iii) $\Rightarrow$ (ii) follows from Lemma 1.4 (i) by putting $\mathrm{c}=\mathrm{a} \wedge \mathrm{b}$.

(ii) $\Rightarrow(v)$. Suppose (ii) holds. Let $\mathrm{z} \in<\mathrm{a} \vee \mathrm{b}, \mathrm{c}>_{\mathrm{d}}$. Then by (ii), $\mathrm{z}=\mathrm{x} \wedge \mathrm{y}$,

where $x \vee a \geq b$ and $y \vee b \geq a$. Also $x \vee a=x \vee a \vee b \geq z \vee a \vee b \geq c$.

This implies $\mathrm{x} \in<\mathrm{a}, \mathrm{c}>_{\mathrm{d}}$. Similarly, $\mathrm{y} \in<\mathrm{b}, \mathrm{c}>_{\mathrm{d}}$.

Hence $\mathrm{z}=\mathrm{x} \wedge \mathrm{y} \in<\mathrm{a}, \mathrm{c}>_{\mathrm{d}} \vee<\mathrm{b}, \mathrm{c}>_{\mathrm{d}}$ and

so $<\mathrm{a} \vee \mathrm{b}, \mathrm{c}>_{\mathrm{d}} \subseteq<\mathrm{a}, \mathrm{c}>_{\mathrm{d}} \vee<\mathrm{b}, \mathrm{c}>_{\mathrm{d}}$.

Since the reverse inequality is obvious, so (v) holds.

(v) $\Rightarrow(\mathbf{i})$. Consider an interval [a, b] in (n]. For $\mathrm{x} \in[\mathrm{a}, \mathrm{b}], \mathrm{a}<\mathrm{b}$, let $[x)^{\text {od }}=\{y \in[a, b]: y \vee x=b\}$. Clearly $[x)^{\text {od }}=<x, a>_{d} \cap[a, b]$.

Then Lemma 1.4. for any $\mathrm{x}, \mathrm{y} \in[\mathrm{a}, \mathrm{b}]$, we have,

$\left[<\mathrm{x}, \mathrm{a}>_{\mathrm{d}} \vee<\mathrm{y}, \mathrm{a}>_{\mathrm{d}}\right] \cap[\mathrm{a}, \mathrm{b}]=\left(<\mathrm{x}, \mathrm{a}>_{\mathrm{d}} \cap[\mathrm{a}, \mathrm{b}]\right) \vee\left(<\mathrm{y}, \mathrm{a}>_{\mathrm{d}} \cap[\mathrm{a}, \mathrm{b}]\right)$.

Then by (v), $<\mathrm{x} \vee \mathrm{y}, \mathrm{a}>_{\mathrm{d}} \cap[\mathrm{a}, \mathrm{b}]=[\mathrm{x})^{\mathrm{od}} \vee[\mathrm{y})^{\text {od }}$, which implies $[\mathrm{x} \vee \mathrm{y})^{\mathrm{od}}=[\mathrm{x})^{\text {od }} \vee[\mathrm{y})^{\text {od }}$. Therefore, by Corollary 1.9, [a, b] is normal.

Therefore (n] is relatively normal.

Now we prove our main results of this paper, which are generalizations of Theorem 1.3, [7, Theorem 5] and a result of [6], also see [8]. These give characterizations of those $\mathrm{P}_{\mathrm{n}}(\mathrm{S})$ which are relatively normal. 
Theorem 1.12 Let $\mathrm{n}$ be a central element of a distributive nearlattice. Suppose A, B are two n-ideals of $\mathrm{S}$. Then for all $\mathrm{a}, \mathrm{b}, \mathrm{c} \in \mathrm{S}$ the following conditions are equivalent.

(i) $\quad \mathrm{P}_{\mathrm{n}}(\mathrm{S})$ is relatively normal.

(ii) $<<$ a $>_{\text {n }},<$ b $>_{\mathrm{n}}>\mathrm{v}<<$ b $>_{\mathrm{n}},<\mathrm{a}>_{\mathrm{n}}>=$ S.

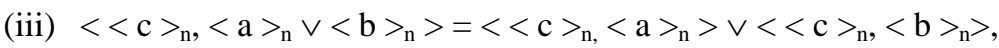
whenever $\mathrm{a} \vee \mathrm{b}$ exists.

(iv) $<\left\langle\text { C }_{\text {n }}, \text { A } \vee \text { B }>=\left\langle<\text { C }>_{\text {n }} \text {, A }\right\rangle \vee<<\text { C }\right\rangle_{\text {n }}$, B $\rangle_{\text {. }}$

(v) $<<$ m (a, n, b) $>_{\text {n }},\left\langle\right.$ c $\left.>_{\text {n }}\right\rangle=\left\langle<\right.$ a $>_{\text {n }},\left\langle\right.$ c $>_{\text {n }}>$ v $\langle<\text { b }\rangle_{\text {n }},\left\langle\right.$ c $>_{\text {n }}>$.

Proof. (i) $\Rightarrow$ (ii). Let $\mathrm{z} \in$ S. Consider the interval $\left.\left.\mathrm{I}=[<\mathrm{a}\rangle_{\mathrm{n}} \cap<\mathrm{b}\right\rangle_{\mathrm{n}} \cap<\mathrm{z}\right\rangle_{\mathrm{n}},\left\langle\mathrm{z}_{\mathrm{n}}\right]$ in $\mathrm{P}_{\mathrm{n}}(\mathrm{S})$. Then $\langle\mathrm{a}\rangle_{\mathrm{n}} \cap\langle\mathrm{b}\rangle_{\mathrm{n}} \cap\langle\mathrm{z}\rangle_{\mathrm{n}}$ is the smallest element of the interval I. By (i), I is normal. Then by [13,Theorem 5.2.5], there exist principal n-ideals $\left\langle\right.$ p ${ }_{n}$,

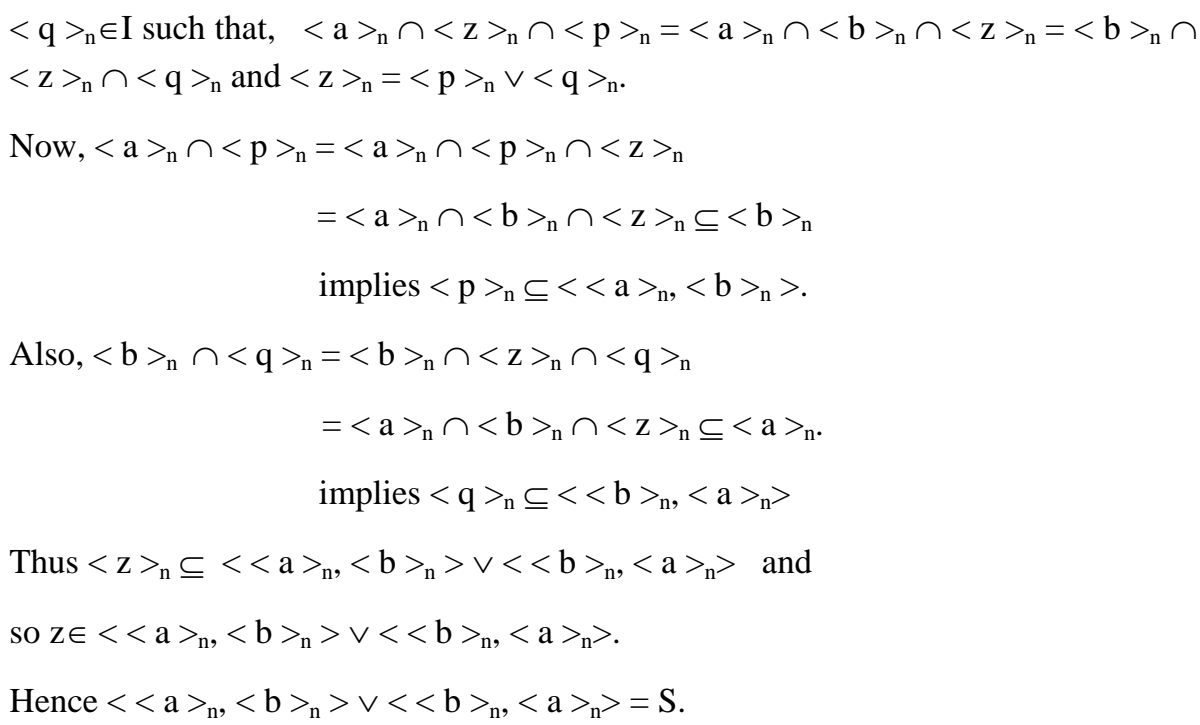

(ii) $\Rightarrow$ (iii). Suppose (ii) holds and a $\vee$ b exists. For (iii), R.H.S. $\subseteq$ L.H.S. is obvious. Now, let $\mathrm{z} \in<<\mathrm{c}>_{\mathrm{n}},<\mathrm{a}>_{\mathrm{n}} \vee<\mathrm{b}>_{\mathrm{n}}>$.

Then $\mathrm{z} \vee \mathrm{n} \in<<\mathrm{c}>_{\mathrm{n}},<\mathrm{a}>_{\mathrm{n}} \vee<\mathrm{b}>_{\mathrm{n}}>$ and $\mathrm{m}(\mathrm{z} \vee \mathrm{n}, \mathrm{n}, \mathrm{c}) \in<\mathrm{a}>_{\mathrm{n}} \vee<\mathrm{b}>_{\mathrm{n}}$.

That is, $m(z \vee n, n, c) \in[a \wedge b \wedge n, a \vee b \vee n]$.

This implies $(\mathrm{z} \vee \mathrm{n}) \wedge(\mathrm{c} \vee \mathrm{n}) \leq \mathrm{a} \vee \mathrm{b} \vee \mathrm{n}$.

Now, by (ii), $\mathrm{z} \vee \mathrm{n} \in<<\mathrm{a}>_{\mathrm{n}},\left\langle\mathrm{b}>_{\mathrm{n}}>\vee<<\mathrm{b}>_{\mathrm{n}},<\mathrm{a}>_{\mathrm{n}}>\right.$.

So $\mathrm{z} \vee \mathrm{n} \leq(\mathrm{p} \vee \mathrm{n}) \vee(\mathrm{q} \vee \mathrm{n})$ for some $\mathrm{p} \vee \mathrm{n} \in<<\mathrm{a}>_{\mathrm{n}},<\mathrm{b}>_{\mathrm{n}}>$ and $\mathrm{q} \vee \mathrm{n} \in<<\mathrm{b}>_{\mathrm{n}},<\mathrm{a}>_{\mathrm{n}}>$. 
Hence, $\mathrm{z} \vee \mathrm{n}=((\mathrm{z} \vee \mathrm{n}) \wedge(\mathrm{p} \vee \mathrm{n})) \vee((\mathrm{z} \vee \mathrm{n}) \wedge(\mathrm{q} \vee \mathrm{n}))=\mathrm{r} \vee \mathrm{t}$ (say).

Now, $m(p \vee n, n, a)=(p \vee n) \wedge(a \vee n) \leq(b \vee n)$

So $\mathrm{b} \wedge \mathrm{n} \leq \mathrm{r} \wedge(\mathrm{a} \vee \mathrm{n}) \leq \mathrm{b} \vee \mathrm{n}$. Hence, $\mathrm{r} \wedge(\mathrm{c} \vee \mathrm{n})=\mathrm{r} \wedge(\mathrm{z} \vee \mathrm{n}) \wedge(\mathrm{c} \vee \mathrm{n})$

$$
\begin{aligned}
& \leq \mathrm{r} \wedge(\mathrm{a} \vee \mathrm{b} \vee \mathrm{n}) \\
& =(\mathrm{r} \wedge(\mathrm{a} \vee \mathrm{n})) \vee(\mathrm{r} \wedge(\mathrm{b} \vee \mathrm{n})) \\
& \leq(\mathrm{b} \vee \mathrm{n})
\end{aligned}
$$

This implies $\mathrm{r} \in\left\langle\langle\mathrm{c}\rangle_{\mathrm{n}},\langle\mathrm{b}\rangle_{\mathrm{n}}\right\rangle$. Similarly, $\mathrm{t} \in\left\langle\langle\mathrm{c}\rangle_{\mathrm{n}},\langle\mathrm{a}\rangle_{\mathrm{n}}\right\rangle$.

Hence $\left.\mathrm{z} \vee \mathrm{n} \in<\langle\mathrm{c}\rangle_{\mathrm{n}},\langle\mathrm{a}\rangle_{\mathrm{n}}\right\rangle \vee<\langle\mathrm{c}\rangle_{\mathrm{n}},\langle\mathrm{b}\rangle_{\mathrm{n}}>$.

Again, $\mathrm{z} \in\left\langle\left\langle\mathrm{c}_{\mathrm{n}},\langle\mathrm{a}\rangle_{\mathrm{n}} \vee\langle\mathrm{b}\rangle_{\mathrm{n}}\right\rangle\right.$ implies $\mathrm{z} \wedge \mathrm{n} \in\left\langle\langle\mathrm{c}\rangle_{\mathrm{n}},\langle\mathrm{a}\rangle_{\mathrm{n}} \vee\left\langle\mathrm{b}_{\mathrm{n}_{\mathrm{n}}}\right\rangle\right.$. Then a dual calculation of above shows that $\mathrm{z} \wedge \mathrm{n} \in\left\langle<\mathrm{c}>_{\mathrm{n}},\langle\mathrm{a}\rangle_{\mathrm{n}}\right\rangle \vee<\left\langle\mathrm{c}_{\mathrm{n}}\right.$,

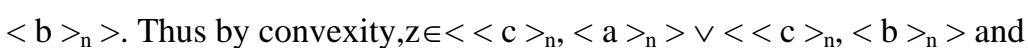

so L.H.S. $\subseteq$ R.H.S. Hence (iii) holds.

(iii) $\Rightarrow$ (iv). Suppose (iii) holds. In (iv), R.H.S. $\subseteq$ L.H.S. is obvious.

Now let $\mathrm{x} \in<<\mathrm{c}>_{\mathrm{n}}, \mathrm{A} \vee \mathrm{B}>$. Then $\mathrm{x} \vee \mathrm{n} \in<\left\langle\mathrm{c}>_{\mathrm{n}}, \mathrm{A} \vee \mathrm{B}>\right.$.

Thus $m(x \vee n, n, c) \in A \vee B$. Now $m(x \vee n, n, c)=(x \vee n) \wedge(n \vee c) \geq n$ implies $\mathrm{m}(\mathrm{x} \vee \mathrm{n}, \mathrm{n}, \mathrm{c}) \in(\mathrm{A} \vee \mathrm{B}) \cap[\mathrm{n})$. Hence by Theorem 1.1(ii),

$\mathrm{x} \vee \mathrm{n} \in<<\mathrm{C}>_{\mathrm{n}},(\mathrm{A} \cap[\mathrm{n})) \vee(\mathrm{B} \cap[\mathrm{n}))>$

$=\vee_{\mathrm{r} \in(\mathrm{A} \cap[\mathrm{n})) \vee(\mathrm{B} \cap[\mathrm{n}))}\left\langle\langle\mathrm{C}\rangle_{\mathrm{n}},\langle\mathrm{r}\rangle_{\mathrm{n}}\right\rangle$. But by [12, Theorem 1.4],

$r \in(A \cap[n)) \vee(B \cap[n))$ implies $r=s \vee t$ for some $s \in A, t \in B$ and

s, t $\geq$ n. Then by (iii), $\left\langle\left\langle\mathrm{c}_{\mathrm{n}},\langle\mathrm{r}\rangle_{\mathrm{n}}\right\rangle=\left\langle\left\langle\mathrm{c}_{\mathrm{n}},\langle\mathrm{s} \vee \mathrm{t}\rangle_{\mathrm{n}}\right\rangle\right.\right.$

$$
\begin{aligned}
& \left.=\left\langle\langle\mathrm{C}\rangle_{\mathrm{n}},\langle\mathrm{s}\rangle_{\mathrm{n}} \vee<\mathrm{t}\right\rangle_{\mathrm{n}}\right\rangle \\
& =\left\langle\langle\mathrm{C}\rangle_{\mathrm{n}},\langle\mathrm{s}\rangle_{\mathrm{n}}\right\rangle \mathrm{v}\left\langle\langle\mathrm{C}\rangle_{\mathrm{n}},\langle\mathrm{t}\rangle_{\mathrm{n}}\right\rangle \\
& \subseteq<<\mathrm{C}>_{\mathrm{n}}, \mathrm{A}>\mathrm{v}<\langle\mathrm{C}\rangle_{\mathrm{n}}, \mathrm{B}>
\end{aligned}
$$

Hence $\mathrm{x} \vee \mathrm{n} \in<\left\langle\mathrm{c}>_{\mathrm{n}}, \mathrm{A}>\vee<<\mathrm{c}>_{\mathrm{n}}\right.$, B $\rangle$. Also $\mathrm{x} \in<<\mathrm{c}>_{\mathrm{n}}, \mathrm{A} \vee \mathrm{B}>$ implies

$\mathrm{x} \wedge \mathrm{n} \in<<\mathrm{C}>_{\mathrm{n}}, \mathrm{A} \vee \mathrm{B}>$.

Since $m(x \wedge n, n, c)=(x \wedge n) \vee(x \wedge c) \leq n$,

so $\mathrm{x} \wedge \mathrm{n} \in<<\mathrm{c}>_{\mathrm{n}},(\mathrm{A} \vee \mathrm{B}) \cap(\mathrm{n}]>$.

Then, by Theorem 1.1(ii), $\mathrm{x} \wedge \mathrm{n} \in<\langle\mathrm{c}\rangle_{\mathrm{n}}$, $\left.(\mathrm{A} \cap(\mathrm{n}]) \vee(\mathrm{B} \cap(\mathrm{n}])\right\rangle$

$$
=\vee_{\mathrm{l} \in(\mathrm{A} \cap(\mathrm{n}]) \vee(\mathrm{B} \cap(\mathrm{n}])}<<\mathrm{C}>_{\mathrm{n}},<\mathrm{l}>_{\mathrm{n}} .
$$


Again, using [12,Theorem 1.4], we see that $\mathrm{l}=\mathrm{p} \wedge \mathrm{q}$ where $\mathrm{p} \in \mathrm{A}, \mathrm{q} \in \mathrm{B}$ and

p, $\mathrm{q} \leq \mathrm{n}$. Then by (iii), $\left\langle\left\langle\mathrm{c}_{\mathrm{n}},\langle\mathrm{l}\rangle_{\mathrm{n}}\right\rangle=\left\langle\left\langle\mathrm{c}_{\mathrm{n}},\langle\mathrm{p} \wedge \mathrm{q}\rangle_{\mathrm{n}}\right\rangle\right.\right.$

$$
\begin{aligned}
& =<<\mathrm{c}>_{\mathrm{n}},<\mathrm{p}>_{\mathrm{n}} \vee<\mathrm{q}>_{\mathrm{n}}> \\
& \left.=\langle<\mathrm{c}\rangle_{\mathrm{n}},\langle\mathrm{p}\rangle_{\mathrm{n}}\right\rangle \mathrm{v}<\left\langle\mathrm{c}>_{\mathrm{n}},\left\langle\mathrm{q}>_{\mathrm{n}}\right\rangle\right. \\
& \subseteq<<\mathrm{C}>_{\mathrm{n}}, \mathrm{A}>\vee<\left\langle\mathrm{C}>_{\mathrm{n}}, \mathrm{B}>\right.
\end{aligned}
$$

Hence $\left.\left.\mathrm{x} \wedge \mathrm{n} \in\langle<\mathrm{c}\rangle_{\mathrm{n}}, \mathrm{A}\right\rangle \vee<\langle\mathrm{c}\rangle_{\mathrm{n}}, \mathrm{B}\right\rangle$. Therefore, by convexity, $\left.\mathrm{x} \in\langle<\mathrm{c}\rangle_{\mathrm{n}}, \mathrm{A}\right\rangle \mathrm{v}\left\langle\langle\mathrm{c}\rangle_{\mathrm{n}}, \mathrm{B}>\right.$ and so L.H.S. $\subseteq$ R.H.S. Thus (iv) holds.

(iv) $\Rightarrow$ (iii) is trivial.

(ii) $\Rightarrow$ (v). Suppose (ii) holds. In (v), R.H.S. $\subseteq$ L.H.S. is obvious.

Now let $\mathrm{z} \in<<\mathrm{m}(\mathrm{a}, \mathrm{n}, \mathrm{b})>_{\mathrm{n}},<\mathrm{c}>_{\mathrm{n}}>$ which implies

$\mathrm{z} \vee \mathrm{n} \in<<\mathrm{m}(\mathrm{a}, \mathrm{n}, \mathrm{b})>_{\mathrm{n}},\left\langle\mathrm{c}>_{\mathrm{n}}>\right.$.

By (ii), $\mathrm{z} \vee \mathrm{n} \in<<\mathrm{a}>_{\mathrm{n}},<\mathrm{b}>_{\mathrm{n}}>\vee<<\mathrm{b}>_{\mathrm{n}},<\mathrm{a}>_{\mathrm{n}}>$. Then by

[12,Theorem 1.4], $\mathrm{z} \vee \mathrm{n}=\mathrm{x} \vee \mathrm{y}$ for some $\mathrm{x} \in<<\mathrm{a}>_{\mathrm{n}},\left\langle\mathrm{b}>_{\mathrm{n}}>\right.$ and $\left.\mathrm{y} \in\langle<\mathrm{b}\rangle_{\mathrm{n}},\langle\mathrm{a}\rangle_{\mathrm{n}}\right\rangle$ and $\mathrm{x}, \mathrm{y} \geq \mathrm{n}$. Thus, $\left.\langle\mathrm{x}\rangle_{\mathrm{n}} \cap\langle\mathrm{a}\rangle_{\mathrm{n}} \subseteq<\mathrm{b}\right\rangle_{\mathrm{n}}$ and so $\langle\mathrm{x}\rangle_{\mathrm{n}} \cap\langle\mathrm{a}\rangle_{\mathrm{n}}=\langle\mathrm{x}\rangle_{\mathrm{n}} \cap\langle\mathrm{a}\rangle_{\mathrm{n}} \cap\langle\mathrm{b}\rangle_{\mathrm{n}} \subseteq\langle\mathrm{z} \vee \mathrm{n}\rangle_{\mathrm{n}} \cap\langle\mathrm{a}\rangle_{\mathrm{n}} \cap\langle\mathrm{b}\rangle_{\mathrm{n}}$ $=\left\langle\mathrm{z} \vee \mathrm{n}>_{\mathrm{n}} \cap<\mathrm{m}(\mathrm{a}, \mathrm{n}, \mathrm{b})>_{\mathrm{n}} \subseteq<\mathrm{c}>_{\mathrm{n}}\right.$.

This implies $\left.\mathrm{x} \in<\langle\mathrm{a}\rangle_{\mathrm{n}},\langle\mathrm{c}\rangle_{\mathrm{n}}\right\rangle$. Similarly, $\left.\mathrm{y} \in<\langle\mathrm{b}\rangle_{\mathrm{n}},\langle\mathrm{c}\rangle_{\mathrm{n}}\right\rangle$ and so

$\left.\mathrm{z} \vee \mathrm{n} \in\langle<\mathrm{a}\rangle_{\mathrm{n}},\langle\mathrm{c}\rangle_{\mathrm{n}}\right\rangle \vee\left\langle\langle\mathrm{b}\rangle_{\mathrm{n}},\langle\mathrm{c}\rangle_{\mathrm{n}}\right\rangle$. Similarly, a dual calculation above shows that $\mathrm{z} \wedge \mathrm{n} \in<<\mathrm{a}>_{\mathrm{n}},\left\langle\mathrm{c}>_{\mathrm{n}}>\vee<\left\langle\mathrm{b}>_{\mathrm{n}},\left\langle\mathrm{c}>_{\mathrm{n}}\right\rangle\right.\right.$. Thus by convexity,

$\left.\mathrm{z} \in<<\mathrm{a}\rangle_{\mathrm{n}},\langle\mathrm{c}\rangle_{\mathrm{n}}\right\rangle \mathrm{v}<\langle\mathrm{b}\rangle_{\mathrm{n}},\left\langle\mathrm{c}>_{\mathrm{n}}>\right.$ and so L.H.S. $\subseteq$ R.H.S. Hence (v) holds.

(v) $\Rightarrow$ (i). Suppose (v) holds. Let a, b, c $\geq$ n.

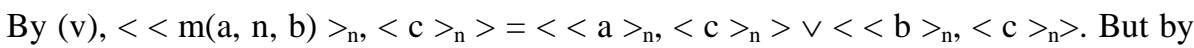
Lemma 1.5(i), this is equivalent to $\langle\mathrm{a} \wedge \mathrm{b}, \mathrm{c}>=\langle\mathrm{a}, \mathrm{c}\rangle \vee<\mathrm{b}, \mathrm{c}>$. Then by

[10, Theorem 3.3.5], this shows that [n) is relatively normal. Similarly, for a, b, c $\leq$ $\mathrm{n}$, using Lemma 1.5(ii) and Theorem 1.11, we find that $(\mathrm{n}]$ is relatively normal. Therefore by [13,Theorem 1.5 .2$], \mathrm{P}_{\mathrm{n}}(\mathrm{S})$ is relatively normal.

Finally we need to prove that (iii) $\Rightarrow$ (i).

Suppose (iii) holds. Let a, b, c $\in \mathrm{S} \cap[\mathrm{n})$.

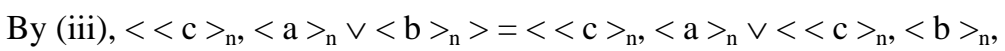

when ever a $\mathrm{v}$ b exists. 
But by Lemma 1.6(i), this is equivalent to

$$
<\mathrm{c}, \mathrm{a} \vee \mathrm{b}>=<\mathrm{c}, \mathrm{a}>\vee<\mathrm{c}, \mathrm{b}>\text {. }
$$

Then by Lemma 1.5, this shows that [n) is relatively normal.

Similarly, for a, b,c $\leq \mathrm{n}$, using the Lemma 1.6(ii) and Theorem 1.11, we find that (n] is relatively normal. Therefore by [13, Theorem 1.5.2], $\mathrm{P}_{\mathrm{n}}(\mathrm{S})$ is relatively normal.

By [5], [7], and [6] we know that a lattice is relatively normal if and only if any two incomparable prime ideals are co-maximal. [9] extended this result for nearlattices. We conclude this paper by proving the following result, which is a generalization of [10, Theorem 3.3.10].

Theorem 1.13 Let $\mathrm{S}$ be a distributive nearlattice. If $\mathrm{n}$ is central in $\mathrm{S}$, then the following conditions are equivalent.

(i) $\mathrm{P}_{\mathrm{n}}(\mathrm{S})$ is relatively normal.

(ii) Any two incomparable prime $\mathrm{n}$-ideals $\mathrm{P}$ and $\mathrm{Q}$ are co-maximal, i.e. $\mathrm{P} \vee \mathrm{Q}=\mathrm{S}$.

Proof. (i) $\Rightarrow$ (ii). Suppose (i) holds. Let P and Q be two incomparable prime

n-ideals of $\mathrm{S}$. Then there exist $\mathrm{a}, \mathrm{b} \in \mathrm{S}$ such that $\mathrm{a} \in \mathrm{P}-\mathrm{Q}$ and $\mathrm{b} \in \mathrm{Q}-\mathrm{P}$.

Then $\langle\mathrm{a}\rangle_{\mathrm{n}} \subseteq \mathrm{P}-\mathrm{Q}$ and $\left\langle\mathrm{b}>_{\mathrm{n}} \subseteq \mathrm{Q}-\mathrm{P}\right.$. Since by (i), $\mathrm{P}_{\mathrm{n}}(\mathrm{S})$ is relatively normal, so by [13, Theorem 5.2.8], $\left.<<\mathrm{a}>_{\mathrm{n}},\langle\mathrm{b}\rangle_{\mathrm{n}}\right\rangle \mathrm{v}<\left\langle\mathrm{b}>_{\mathrm{n}},\langle\mathrm{a}\rangle_{\mathrm{n}}\right\rangle=\mathrm{S}$.

But as P, Q are prime, so it is easy to see that $<<\mathrm{a}>_{\mathrm{n}},<\mathrm{b}>_{\mathrm{n}}>\subseteq \mathrm{Q}$ and

$<<\mathrm{b}>_{\mathrm{n}},<\mathrm{a}>_{\mathrm{n}}>\subseteq \mathrm{P}$. Therefore, $\mathrm{S} \subseteq \mathrm{P} \vee \mathrm{Q}$ and so $\mathrm{P} \vee \mathrm{Q}=\mathrm{S}$. Thus (ii) holds.

(ii) $\Rightarrow$ (i). Suppose (ii) holds. Let $\mathrm{P}_{1}$ and $\mathrm{Q} 1$ be two incomparable prime ideals of [n). Then by [13, Lemma 1.5.5], there exist two incomparable prime ideals $P$ and $Q$ of $S$ such that $\mathrm{P}_{1}=\mathrm{P} \cap[\mathrm{n})$ and $\mathrm{Q}_{1}=\mathrm{Q} \cap[\mathrm{n})$. Since $\mathrm{n} \in \mathrm{P}_{1}$ and $\mathrm{n} \in \mathrm{Q}_{1}$, so by

[12, Lemma 1.7], $\mathrm{P}$ and $\mathrm{Q}$ are in fact two incomparable prime n-ideals of S. Then by (ii), $\mathrm{P} \vee \mathrm{Q}=\mathrm{S}$.

Therefore, $\mathrm{P}_{1} \vee \mathrm{Q}_{1}=(\mathrm{P} \vee \mathrm{Q}) \cap[\mathrm{n})$

$$
\begin{aligned}
& =S \cap[n) \\
& =[n) .
\end{aligned}
$$

Thus by [10, Theorem 3.3.10], [n) is relatively normal.

Similarly, considering two prime filters of (n] and proceeding as above and using the dual result of [10, Theorem 3.3.10] we find that (n] is relatively normal. Therefore, by [13, Theorem 1.5.2], $P_{n}(S)$ is relatively normal. 


\section{REFERENCES}

1. W.H. CoRnish, n-Normal lattices, Proc. Amer. Math. Soc. 1(45),48-54(1974).

2. A.S. A. NoOR AND M. A. LATIF, Normal nearlattices, The Rajshahi University Studies (PartB), Vol. IX, 69-74(1982).

3. A.S.A.NooR, n-Normal nearlattices, The Rajshahi University Studies (Part-B) X-XI: 217222,(1983).

4. M.A. Ali, A study on finitely generated n-ideals of a lattice, Ph.D. Thesis, Rajshshi University, Rajshahi(2000).

5. W.H. CoRnish, Normal lattices, J. Austral. Math. Soc. 14, 200-215(1972).

6. B.A. DAVEY, Some annihilator conditions on distributive lattices, Algebra Universalis Vol. 4, 3, 316-322(1974).

7. M. MANDELKER, Relative annihilators in lattices, Duke Math. J. 40, 377-386(1970).

8. A.S.A. NOOR AND A.K.M.S. IsLAM, Relative annihilators in nearlattices, The Rajshahi University Studies (Part-B), J. Sci. 25, 117-120(1997).

9. A.S.A. NOOR AND M.B. RAHMAN, Some characterizations of relatively normal nearlattices, Submitted to SEA Bull. Math.

10. M.B. Rahman, A study on distributive nearlattices, Ph.D. Thesis, Rajshahi university, Rajshahi (1995).

11. Shiuly Akhtar, A study on principal n-ideals of a nearlattice, Ph.D. Thesis, Rajshahi University, Rajshahi(2004).

12. M. S. RaihAn AND M. A. LATIF, A Generalization of Stone's Separation Theorem for Nearlattices, Accepted in the Journal of Mathematics and Mathematical Sciences, Jahangirnagar University Mathematics Department.

13. M.S. RAIHAN, On Principal n-Ideals of a Distributive Nearlattice, Ph.D. Thesis, Rajshahi University, Rajshahi(2006).

14. M. S. Raihan, Caracterizations of Normal Nearlattices in terms of n-ideals, accepted in the Rajshahi University Journal of Sciences. 